\title{
What's in a Name? Analyzing the Influence of Brand Names on Entertainment Product Success: An Abstract
}

\author{
Nora Paehler vor der Holte, Fabian Gless, Ann-Kristin Knapp, Utz Riehl, \\ and Thorsten Hennig-Thurau
}

\begin{abstract}
Research on motion picture success has considered a multitude of different factors that influence the success of a movie. Nevertheless, one of the most prominent characteristics of a movie has been widely ignored: its title. As movie titles, which are considered equivalent to brand names, can give consumers an idea of how a movie will look or feel like, it could be used as a first reference point to inform consumers' purchase decisions. Although managers reportedly have the feeling that a brand name alone can influence sales, empirical evidence for this influence is limited. In this research, we apply a unique two-step procedure to investigate the influence of movie titles on motion picture success. First, we introduce a consumerlevel model to analyze the role of the movie title in the consumer decision-making process. Second, we extend the consumer-level model to the market level, incorporating behavioral data on actual product sales. We thereby shed light on the question whether a title influences the generation of sales when other information cues such as advertising and existing brands are available.
\end{abstract}

N.P. vor der Holte $(\bowtie) \bullet$ F. Gless $\bullet$ A.-K. Knapp •U. Riehl • T. Hennig-Thurau

University of Muenster, Münster, Germany

e-mail: nora.paehlervorderholte@wiwi.uni-muenster.de; fmgless@gmail.com; ann-kristin.

knapp@wiwi.uni-muenster.de; utz.riehl@wiwi.uni-muenster.de; tht@wiwi.uni-muenster.de 